\title{
Mechanically assisted bidirectional cavopulmonary shunt in neonates and infants: An acute human pilot study
}

Osami Honjo, MD, PhD, ${ }^{a}$ Sandra L. Merklinger, RN, PhD, ${ }^{\mathrm{a}}$ John B. Poe, MSc, ${ }^{\mathrm{a}}$ Anne-Marie Guerguerian, MD, PhD, ${ }^{\mathrm{b}}$ Hargen Zhang, MD, ${ }^{\mathrm{a}}$ Katherine L. Taylor, $\mathrm{MD},{ }^{\mathrm{c}}$ and Glen S. Van Arsdell, MD ${ }^{\mathrm{d}}$

\begin{abstract}
Objective: Poor survival following surgical palliation for hypoplastic left heart syndrome (HLHS) raises the question of the need for a paradigm shift. This is the first human study to investigate the possibility of primary "in-series" palliation in neonates and infants with HLHS in an acute setting with the aid of 2 types of mechanical assist: superior vena cava (SVC)-to-pulmonary artery (PA) pump assist and SVC-to-right atrium (RA) oxygenation assist.
\end{abstract}

Methods: By rearranging the cannula sites and flow rates for modified ultrafiltration, 2 types of mechanically assisted bidirectional cavopulmonary shunt (BCPS) circulation were simulated for 20 minutes. Three neonates undergoing a stage I Norwood procedure were assigned to SVC-PA pump assist, and 3 infants undergoing stage II BCPS were assigned to SVC-RA oxygenation assist. Hemodynamic parameters, blood gas values, and arterial $\left(\mathrm{SaO}_{2}\right)$ and regional cerebral tissue $\left(\mathrm{rCTO}_{2}\right)$ saturations were analyzed.

Results: All 6 patients completed the study without hemodynamic compromise. In the SVC-PA pump assist group, a mean arterial pressure $>40 \mathrm{~mm} \mathrm{Hg}$ was maintained. SVC pressure was lower $(P=.01)$ and cerebral perfusion pressure (CPP) was higher $(P=.03)$ during the last 10 minutes of assist compared with Norwood physiology. $\mathrm{SaO}_{2}>80 \%, \mathrm{rCTO}_{2}>60 \%$, and mixed venous saturation $\geq 59 \%$ were maintained, comparable to values with Norwood physiology. In the SVCRA oxygenation assist group, with full or 50\% support, mean blood pressure $>50 \mathrm{~mm} \mathrm{Hg}$, SVC pressure $<15 \mathrm{~mm} \mathrm{Hg}$, mixed venous saturation $>50 \%$, and CPP $>40 \mathrm{~mm} \mathrm{Hg}$ were maintained, which were comparable to BCPS physiology.

Conclusions: Two types of mechanical assist to support primary in-series palliation are feasible in the acute setting. Both modes of mechanical assist maintained oxygenation, as well as systemic and cerebral perfusion. (J Thorac Cardiovasc

Surg 2017;153:441-7)

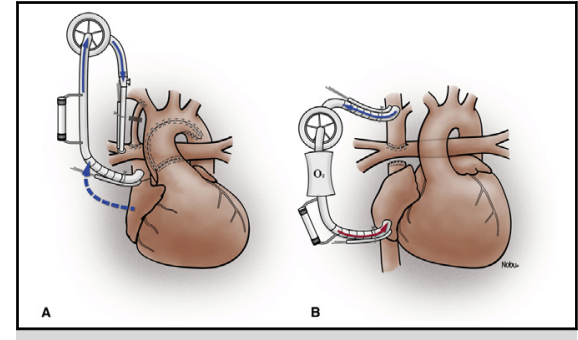

Two types of mechanical assist systems to support primary in-series palliation.

\section{Central Message}

This is the first proof-of-concept human study of mechanically assisted primary bidirectional cavopulmonary shunt in neonates and infants with hypoplastic left heart syndrome.

Perspective

This is the first proof-of-concept human study of mechanically assisted primary bidirectional cavopulmonary shunt in patients with hypoplastic left heart syndrome. This study demonstrates the feasibility and safely of 2 types of mechanically assisted primary in-series palliation, which can be an alternative to conventional surgical palliation.

See Editorial Commentary page 448.
Regardless of palliation type and despite incremental improvements over the last 2 decades, staged surgical

\footnotetext{
From ${ }^{a}$ The Labatt Family Heart Centre, ${ }^{b}$ Department of Critical Care Medicine, ${ }^{\mathrm{c}}$ Department of Anaesthesia, and ${ }^{\mathrm{d}}$ Division of Cardiovascular Surgery, The Hospital for Sick Children and The University of Toronto, Toronto, Ontario, Canada.

This study was funded in part by the Heart and Stroke Foundation of Ontario (grant No. NA7103).

Received for publication March 15, 2016; revisions received Sept 9, 2016; accepted for publication Sept 14, 2016; available ahead of print Nov 4, 2016.

Address for reprints: Glen S. Van Arsdell, MD, Division of Cardiovascular Surgery, Hospital for Sick Children, 555 University Ave, Toronto, Ontario M5G 1X8, Canada (E-mail: glen.vanarsdell@sickkids.ca). 0022-5223/\$36.00

Copyright (c) 2016 Published by Elsevier Inc. on behalf of The American Association for Thoracic Surgery

http://dx.doi.org/10.1016/j.jtcvs.2016.09.048
}

palliation for patients with hypoplastic left heart syndrome (HLHS) is associated with up to $30 \%$ mortality by age 1 year. ${ }^{1-3}$ The survival curve follows a similar pattern of significant early mortality and interstage attrition through stage II, after which the slope of the curve shallows. A key difference between stage I and stage II circulation is that of "in-parallel" versus "in-series" circulation. To

Scanning this QR code will take you to the article title page.

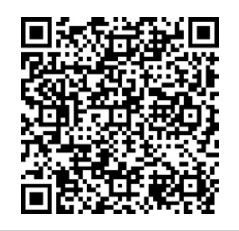




$$
\begin{aligned}
& \text { Abbreviations and Acronyms } \\
& \text { BCPS = bidirectional cavopulmonary shunt } \\
& \mathrm{BT}=\text { Blalock-Taussig } \\
& \mathrm{CPB}=\text { cardiopulmonary bypass } \\
& \mathrm{CPP}=\text { cerebral perfusion pressure } \\
& \text { HLHS = hypoplastic left heart syndrome } \\
& \text { MUF }=\text { modified ultrafiltration } \\
& \mathrm{PA}=\text { pulmonary artery } \\
& \mathrm{pCO}_{2}=\text { partial pressure of carbon dioxide } \\
& \mathrm{pO}_{2}=\text { partial pressure of oxygen } \\
& \text { PVR = pulmonary vascular resistance } \\
& \mathrm{RA}=\text { right atrium } \\
& \mathrm{rCTO}_{2}=\text { regional cerebral tissue saturation } \\
& \mathrm{SaO}_{2}=\text { arterial saturation } \\
& \mathrm{SVC}=\text { superior vena cava } \\
& \mathrm{VO}_{2}=\text { oxygen consumption }
\end{aligned}
$$

overcome the difference in hemodynamic stability between the 2 circulation types, Norwood and colleagues ${ }^{4}$ and Reddy and colleagues ${ }^{5}$ reported very early in-series palliation. Either failure or substantially less-than-optimal outcomes were reported, likely due to immature lung vasculature and elevated pulmonary vascular resistance (PVR). ${ }^{4,5}$

Our acute animal experiments have demonstrated the feasibility of primary in-series circulation with the aid of a mechanical pump. Mechanical cavopulmonary assistie, superior vena cava (SVC)-to-pulmonary artery (PA) pump assist - has been shown to provide adequate blood flow to the pulmonary vasculature through the bidirectional cavopulmonary shunt (BCPS) in an acute setting of high PVR in a neonatal and infantile animal model..$^{6-8}$ Effective drainage of the upper venous system yields an adequate cerebral perfusion profile. ${ }^{6}$ A second assist system, SVC-to-right atrium (RA) pump assist with oxygenation, also was shown to achieve sustainable physiology for a primary BCPS in neonatal pigs, by both partially unloading SVC pressure and also oxygenating the unloaded portion of blood. ${ }^{8}$ The encouraging acute translational animal experience led us to design an acute human study to be performed for the 20 minutes of modified ultrafiltration (MUF) following separation from cardiopulmonary bypass (CPB). By changing the rate of ultrafiltration and the cannula positions, we were able to achieve both types of simulated mechanical assist described noted above. This report presents preliminary data from our pilot study of mechanical cavopulmonary assist applied to human neonates and infants with HLHS for the first time.

\section{PATIENTS AND METHODS}

This study was approved by the Research Ethics Committee at The Hospital for Sick Children, Toronto. Informed consent was obtained from parents. Neonates with HLHS and its variants who were scheduled to undergo a Norwood procedure were considered candidates for the SVC-PA pump assist strategy, and those with single ventricle pathology undergoing BCPS were considered candidates for the SVC-RA oxygenation assist strategy.

\section{Simulation of Mechanically Assisted BCPS With a Modified MUF Circuit}

The 2 types of mechanically assisted BCPS circulation were designed and simulated at the period of MUF using a modified MUF circuit. In the conventional MUF, the blood is drawn from an ascending aortic cannula and is pumped back to a venous cannula after ultrafiltration. ${ }^{9}$ The cannula arrangements were changed to simulate mechanically assisted BCPS. Because the pump assist system was incorporated in the MUF circuit, the study period was limited to 20 minutes, during which time MUF achieved its target fluid removal and hematocrit values.

\section{SVC-PA Pump Assist Strategy at Stage I Palliation}

After a median sternotomy, the baseline SVC blood flow was obtained using an ultrasonic flow probe (Transonic Systems, Ithaca, NY) as a reference for determining the pump flow for the mechanical assist. CPB was performed using a roller pump (Sorin, Milan, Italy) and an oygenator (Quadrox-1; Maquet, Rastatt, Germany). Stage I Norwood palliation was performed with standard surgical techniques and perfusion strategies. ${ }^{10}$ Immediately after termination of $\mathrm{CPB}$, a modified veno-venous MUF was applied, with an outflow cannula to the MUF circuit (a 10-Fr right-angled cannula; Edwards Lifesciences, Irvine, Calif) placed in the SVC and an inflow cannula (8 Fr arterial cannula; Edwards Lifesciences) inserted in the central PA. The inflow cannula was inserted at the stump of the main PA to ensure bidirectional flow to each branch of the PA without distorting branch PA architecture. The SVC was snared, thereby directing all upper venous return to the MUF circuit. The shunt was temporarily occluded with a vascular clip for the duration of the study, which established the equivalent of a mechanically assisted primary BCPS circulation (Figure 1, A). At this point, the inflow blood from the MUF circuit was the sole source of pulmonary blood flow. We also used an additional RA cannula that had a Y-connection to the SVC return tubing, to allow for additional venous blood to be drawn if the pulmonary blood flow requirement exceeded the amount of SVC drainage. The pump flow was determined by the patient's body weight, baseline SVC flow, and SVC pressure during the study.

\section{SVC-RA Oxygenation Assist Strategy}

Baseline SVC blood flow data were obtained as described above. BCPS was performed with standard surgical techniques and perfusion strategies. ${ }^{11}$ SVC-RA oxygenation assist for BCPS circulation was established immediately after termination of CPB. A modified veno-venous MUF was used, with an outflow cannula to the MUF circuit placed in the SVC and an inflow cannula to the body placed in the inferior vena cava or RA (Figure 1, B). The SVC was snared, after which total SVC-RA oxygenation was achieved in the first 10 minutes. With the SVC snare released, incremental declines in the modified MUF circuit flow to $50 \%$ of the initial flow and then to $25 \%$ of the initial flow were achieved at 5-minute intervals. This was done to simulate partial assist or a weaning protocol for a potential chronic assist strategy.

\section{Evaluation}

Hemodynamic parameters, including mean blood pressure and SVC pressure, heart rate, and arterial saturation $\left(\mathrm{SaO}_{2}\right)$, were recorded continuously. The pump flow through the inflow cannula (ie, amount of pulmonary blood flow) was measured using an ultrasonic flow probe placed on the inflow tube. Arterial and venous blood samples were obtained at baseline immediately after termination of CPB and then every 10 minutes throughout the study period. Hemodynamic and blood gas analyses were 


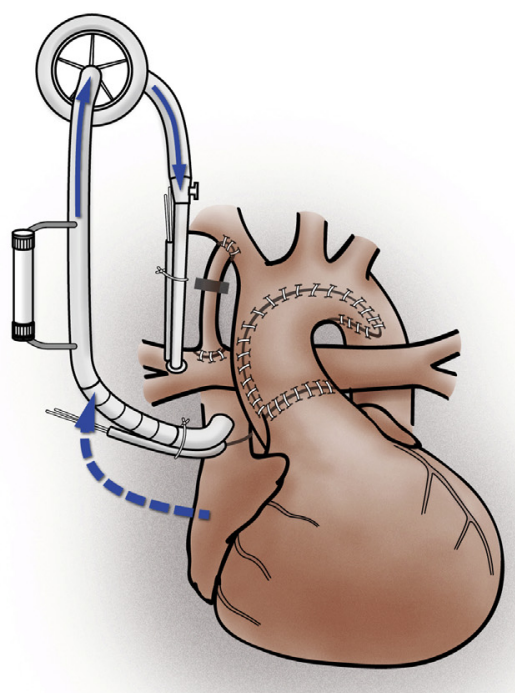

A

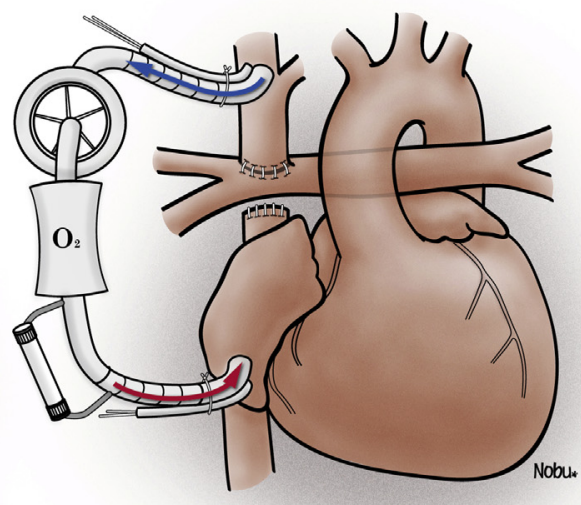

B

FIGURE 1. A, SVC-to-PA pump assist. Blood is removed from the SVC and passed through the MUF circuit. The pump returns the blood to the patient via the PA cannula. The pump flow rate is determined by the SVC flow measured before CPB. The BT shunt was temporarily clipped, making the simulated mechanically assisted BCPS flow the sole source of pulmonary blood. Additional blood volume can be sourced from the RA. Following the 20-minute study, the shunt clip was removed, and the neonate was returned to normal Norwood physiology. B, SVC-RA oxygenation assist. Blood is removed from the patient via the SVC cannula, passed through the MUF, circuit and returned to the patient via the RA or inferior vena cava. The initial pump flow rate is determined by the SVC flow measured before cardiopulmonary bypass.

repeated at 10 minutes after termination of the mechanical assist as selfcontrol data. Regional cerebral tissue oxygen saturation $\left(\mathrm{rCTO}_{2}\right)$ was measured continuously by near-infrared spectroscopy. Oxygen consumption $\left(\mathrm{VO}_{2}\right)$ was also measured by near-infrared spectroscopy, as described previously, ${ }^{12}$ in patients who received SVC-PA pump assist. Cerebral perfusion pressure (CPP) was calculated as the difference between mean arterial pressure and SVC pressure. ${ }^{6}$

\section{Statistical Analysis}

Comparisons between values recorded during mechanical assist and baseline physiology (either Norwood or BCPS) were performed using the Wilcoxon rank-sum test.

\section{RESULTS}

Ten patients were enrolled in the study. One patient who underwent a Norwood procedure with a Blalock-Taussig
(BT) shunt was removed from the study before the intervention owing to hemodynamic instability at the termination of $\mathrm{CPB}$. Three patients did not complete the study because of lack of specialty resource or equipment issues. Data obtained for the remaining 6 patients (SVC-PA pump assist, $\mathrm{n}=3$; SVC-RA oxygenation assist, $\mathrm{n}=3$ ), including body weight and surface area, baseline SVC blood flow, and mechanically assisted BCPS blood flow, are presented in Table 1. A trend is evident toward higher baseline SVC blood flow in infants who underwent stage II BCPS and subsequent SVC-RA oxygenation assist compared with neonates who underwent stage I palliation. No mortality or PA reintervention was associated with PA cannulation in any of the 6 patients.

TABLE 1. Baseline SVC blood flow versus mechanically assisted BCPS blood flow in 2 types of mechanical assist

\begin{tabular}{|c|c|c|c|c|c|c|c|c|c|}
\hline \multirow[b]{2}{*}{ Case } & \multirow[b]{2}{*}{$\mathrm{BW}, \mathbf{k g}$} & \multirow[b]{2}{*}{ BSA, $\mathbf{m}^{2}$} & \multicolumn{3}{|c|}{ Baseline SVC flow } & \multicolumn{4}{|c|}{ Mechanically assisted BCPS flow } \\
\hline & & & $\mathrm{mL} / \mathrm{min}$ & $\mathrm{mL} / \mathrm{kg} / \mathrm{min}$ & $\mathrm{L} / \mathrm{m}^{2} / \mathrm{min}$ & $\mathrm{mL} / \mathrm{min}$ & $\%$ of baseline SVC flow & $\mathrm{mL} / \mathrm{kg} / \mathrm{min}$ & $\mathrm{L} / \mathrm{m}^{2} / \mathrm{min}$ \\
\hline \multicolumn{10}{|c|}{ SVC-PA pump assist } \\
\hline Case 1 & 3.1 & 0.21 & 260 & 83.9 & 1.23 & 270 & 103.8 & 87.1 & 1.28 \\
\hline Case 2 & 3.78 & 0.24 & 270 & 71.4 & 1.13 & 380 & 140.7 & 100.5 & $1.58^{*}$ \\
\hline Case 3 & 3.28 & 0.22 & 340 & 103.5 & 1.54 & 420 & 123.5 & 128 & $1.91 *$ \\
\hline \multicolumn{10}{|c|}{ SVC-RA O ${ }_{2}$ assist } \\
\hline Case 4 & 6.77 & 0.38 & 700 & 103.4 & 1.84 & 640 & 91.4 & 94.5 & 1.68 \\
\hline Case 5 & 5.07 & 0.26 & 480 & 94.7 & 1.84 & 390 & 81.3 & 76.9 & 1.5 \\
\hline Case 6 & 7.13 & 0.4 & 650 & 91.5 & 1.63 & 700 & 107.7 & 98.1 & 1.75 \\
\hline
\end{tabular}

$S V C$, Superior vena cava; $B C P S$, bidirectional cavopulmonary shunt; $B W$, body weight; $B S A$, body surface area; $S V C-P A$, superior vena cava-pulmonary artery; $S V C-R A$, superior vena cava-right atrium. $*$ With additional RA drainage. 

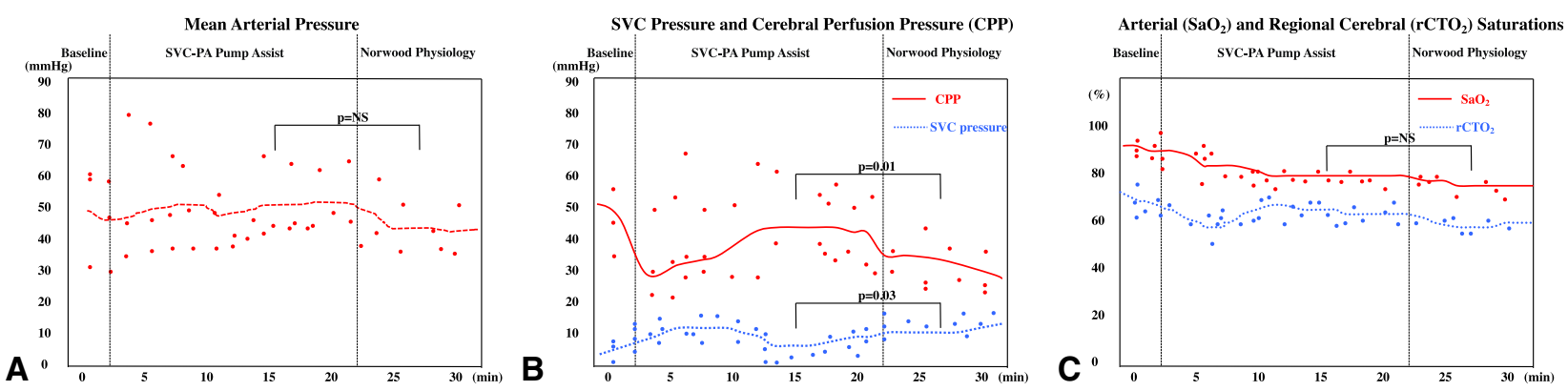

FIGURE 2. Trends in hemodynamics and saturation during SVC-PA pump assist. A, Mean blood pressure $>40 \mathrm{~mm} \mathrm{Hg}$ was maintained. There was no difference in mean arterial pressure between the last 10 minutes of mechanical assist and Norwood physiology $(P$ not significant). B, SVC pressure was lower and CPP was higher during the last 10 minutes of mechanical assist compared with Norwood physiology. $\mathrm{C}, \mathrm{SaO}_{2}>80 \%$ and $\mathrm{rCTO}_{2}>60 \%$ were maintained throughout the study.

\section{SVC-PA Pump Assist}

All 3 patients in this group completed the 20-minute study exhibiting hemodynamic stability. The SVC-PA pump assist system generated $>100 \%$ of baseline SVC blood flow, especially in cases 2 and 3, where additional drainage from the RA was used (Table 1; Figure 1, A, dotted line). The changes in mean arterial and SVC pressures, $\mathrm{SaO}_{2}$, and $\mathrm{rCTO}_{2}$ are illustrated in Figure 2. The mean arterial pressure during SVC-PA pump assist was stable and slightly higher than that in Norwood physiology $(P=$ not significant; Figure 2, A). CPP in the last 10 minutes of the SVC-PA pump assist was significantly higher than that in the self-control Norwood physiology $(P=.01)$, and SVC pressure in the last 10 minutes of the SVC-PA pump assist was significantly lower than that in the Norwood physiology $(P=.03$ ) (Figure 2, $B) . \mathrm{SaO}_{2}$ and $\mathrm{rCTO}_{2}$ during SVC-PA pump assist were comparable to the values in self-control Norwood physiology $(P=$ not significant; Figure 2, C).

Blood gas analysis values for SVC-PA pump assist at 10 minutes and the self-control Norwood physiology are compared in Table 2. There were no significant differences in $\mathrm{pH}$, partial pressure of carbon dioxide $\left(\mathrm{pCO}_{2}\right)$, or partial pressure of oxygen $\left(\mathrm{pO}_{2}\right)$. Mixed venous saturation was maintained in all 3 patients. $\mathrm{VO}_{2}$ was lower during SVCPA pump assist compared with Norwood physiology for the 2 patients in whom $\mathrm{VO}_{2}$ measurements were obtained.

\section{SVC-RA Oxygenation Assist}

None of the 3 patients in this group demonstrated hemodynamic instability during the 20-minute period of SVCRA oxygenation assist. The SVC-RA oxygenation assist system generated $>1.5 \mathrm{~L} / \mathrm{m}^{2} / \mathrm{min}$ of BCPS blood flow in all 3 patients (Table 1). The changes in mean arterial and SVC pressures, $\mathrm{SaO}_{2}$, and $\mathrm{rCTO}_{2}$ are illustrated in Figure 3. The mean arterial pressure during SVC-RA oxygenation assist was stable throughout the study period and comparable to that in BCPS physiology (Figure 3, A).
Compared with BCPS physiology, CPP was comparable or slightly higher during SVC-RA oxygenation assist. SVC pressure was lower during SVC-RA oxygenation assist $(P$ value not available owing to the stepwise decrease in pump flow). $\mathrm{SaO}_{2}$ and $\mathrm{rCTO}_{2}$ were stable during SVCRA oxygenation assist and comparable to the values measured in BCPS physiology at either full flow or 50\% flow support. When the pump flow was reduced to $25 \%$ of the total flow, $\mathrm{SaO}_{2}$ and $\mathrm{rCTO}_{2}$ both declined (Figure 3,C). Blood gas values for SVC-RA oxygenation assist at 10 minutes and BCPS physiology are compared in Table 3. The data show no significant differences in $\mathrm{pH}, \mathrm{pCO}_{2}$, or $\mathrm{pO}_{2}$. Mixed venous saturation was maintained

TABLE 2. Blood gas and oxygen consumption values in SVC-PA pump assist (at 10 minutes) and Norwood physiology

\begin{tabular}{|c|c|c|}
\hline$\underline{\text { Parameters }}$ & SVC-PA pump assist & Norwood physiology \\
\hline \multicolumn{3}{|l|}{$\mathrm{pH}$} \\
\hline Case 1 & 7.28 & 7.32 \\
\hline Case 2 & 7.32 & 7.33 \\
\hline Case 3 & 7.33 & 7.34 \\
\hline \multicolumn{3}{|c|}{$\mathrm{pCO}_{2}, \mathrm{~mm} \mathrm{Hg}$} \\
\hline Case 1 & 39.1 & 32.4 \\
\hline Case 2 & 25.2 & 26 \\
\hline Case 3 & 22.6 & 24.3 \\
\hline \multicolumn{3}{|l|}{$\mathrm{pO}_{2}, \mathrm{~mm} \mathrm{Hg}$} \\
\hline Case 1 & 42.2 & 45.2 \\
\hline Case 2 & 54.7 & 38.2 \\
\hline Case 3 & 40.1 & 43.6 \\
\hline \multicolumn{3}{|c|}{ Mixed venous saturation, $\%$} \\
\hline Case 1 & 68.4 & 62.3 \\
\hline Case 2 & 59 & 59.2 \\
\hline Case 3 & 67.1 & 62 \\
\hline \multicolumn{3}{|c|}{$\mathrm{VO}_{2}, \mathrm{~mL} / \mathrm{kg} / \mathrm{min}$} \\
\hline Case 1 & NA & NA \\
\hline Case 2 & 2.6 & 3.4 \\
\hline Case 3 & 2.5 & 2.7 \\
\hline
\end{tabular}

$S V C-P A$, Superior vena cava-pulmonary artery; $\mathrm{PCO}_{2}$, partial pressure of carbon dioxide; $\mathrm{pO}_{2}$, partial pressure of oxygen; $\mathrm{VO}_{2}$, oxygen consumption; $N A$, not available. 

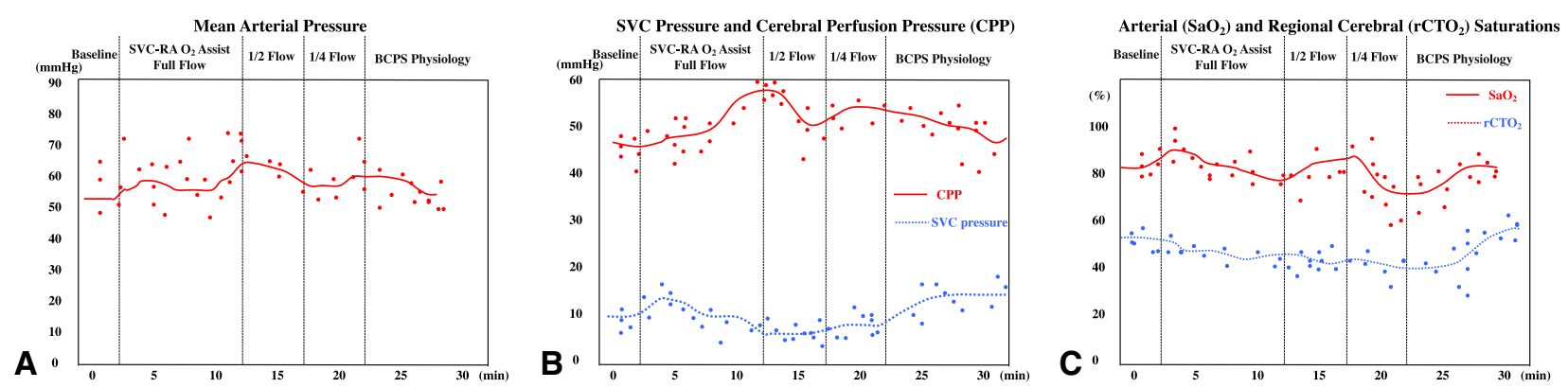

FIGURE 3. Trends in hemodynamics and saturations during SVC-RA oxygenation assist. A, Mean blood pressure $>50 \mathrm{~mm} \mathrm{Hg} \mathrm{was} \mathrm{maintained.} \mathrm{B,} \mathrm{SVC}$ pressure tended to be lower and CPP tended to be higher during the last 10 minutes of mechanical assist compared with $\mathrm{BCPS}_{\mathrm{physiology} . \mathrm{C}, \mathrm{SaO}}>70 \%$ and $\mathrm{rCTO}_{2}>40 \%$ were maintained throughout the study at $25 \%$ assisted flow. It became apparent that maintenance of an SVC filling pressure in the range of 12 to 15 was needed so that the lung would also contribute to oxygenation; that is, there appeared to be a critical filling pressure required for the lung to contribute.

in all 3 patients. $\mathrm{VO}_{2}$ was lower during SVC-RA pump assist compared with Norwood physiology in 2 patients.

\section{DISCUSSION}

With contemporary surgical strategies and perioperative management, overall survival in infants with HLHS and other single-ventricle physiologies remains less than optimal. Although recent series consistently showed significantly improved 30-day survival, ${ }^{1-3}$ the relevance of interstage death and significant ventricular dysfunction remain high and essentially comparable among the currently available palliation strategies. ${ }^{13,14}$ One potential reason for this is the possible fundamental limitations of the "physiological strain" of the in-parallel circulation of stage I palliation. This possibility led us to consider whether the physiological issues of lung immaturity that preclude

TABLE 3. Blood gas values in SVC-RA oxygenation assist (at 10 minutes) and BCPS physiology

\begin{tabular}{lcc}
\hline Parameter & SVC-RA oxygenation assist & BCPS physiology \\
\hline $\mathrm{pH}$ & & \\
Case 4 & 7.45 & 7.43 \\
Case 5 & 7.43 & 7.25 \\
Case 6 & 7.35 & 7.33 \\
$\mathrm{pCO}_{2}, \mathrm{~mm} \mathrm{Hg}$ & & \\
Case 4 & 36.5 & 37 \\
Case 5 & 27 & 35 \\
Case 6 & 24.8 & 23 \\
$\mathrm{pO}_{2}$, mm Hg & & \\
Case 4 & 50 & 52 \\
Case 5 & 50.2 & 51.1 \\
Case 6 & 38.8 & 47 \\
Mixed venous saturation, \% & \\
Case 4 & 60.1 & 55.3 \\
Case 5 & 51.2 & 52.9 \\
Case 6 & 47.6 & 50.2 \\
\hline
\end{tabular}

SVC-RA, Superior vena cava-right atrium; $B C P S$, bidirectional cavopulmonary shunt; $p \mathrm{CO}_{2}$, partial pressure of carbon dioxide; $\mathrm{pO}_{2}$, partial pressure of oxygen. primary in-series circulation (ie, primary cavopulmonary connection) could be overcome. We explored the concept in a series of acute animal experiments, ${ }^{6-8}$ which led us to design an acute human pilot study to be tested in the operating room. The present study has demonstrated the feasibility of mechanically assisted BCPS in neonates and infants in an acute setting in the operating room. All experiments were performed safely without any technical complications. Hemodynamics and metabolic parameters were stable, with an adequate cerebral perfusion profile, throughout the studies.

\section{Design of the Mechanical Assist Systems}

The 2 mechanical assist systems used in this study were designed as theoretic constructs to assist primary BCPS palliation in neonates and very small infants (age $<2$ months). Our hypothesized stage I palliation included aortic arch reconstruction, atrial septectomy, and creation of BCPS as a pulmonary blood source instead of a BT shunt. This is an extension of Dr. Norwood's original idea of primary in-series palliation ${ }^{4}$ but with a mechanical assist. Both mechanical assist systems were designed to overcome the problems associated with immature lungs and pulmonary vascular bed, including high PVR and potentially poor oxygenation and gas exchange capacity. The concept behind SVC-PA pump assist is to augment BCPS flow against the highly resistant pulmonary vasculature and to use the native lung for oxygenation and $\mathrm{CO}_{2}$ exchange. The SVC-RA oxygenation assist system is essentially that of partial assist veno-venous extracorporeal membrane oxygenation, or an artificial lung. Both systems decompress the upper venous system through a cannula in the SVC above the BCPS anastomosis, thereby allowing physiological cerebral blood flow patterns. The physiology is that of a partially saturated in-series circulation (as opposed to the "full" saturation of an in-series Fontan circulation) with a pulmonary-to-systemic flow ratio of $<1: 1$ and a 
demand on the ventricle to pump a normalized single cardiac output.

\section{SVC-PA Pump Assist}

This study shows that adequate oxygenation and $\mathrm{CO}_{2}$ exchange can be achieved by augmenting BCPS flow to the pulmonary circulation in neonates. The baseline SVC flow in the 3 patients in this group ranged from 83 to $103 \mathrm{~mL} / \mathrm{kg} / \mathrm{min}$. The patients maintained $\mathrm{SaO}_{2}$ at $80 \%$ to $85 \%$ throughout the study, with the BCPS flow ranging from 87 to $128 \mathrm{~mL} / \mathrm{kg} / \mathrm{min}$. The 2 patients who had additional RA drainage/flow augmentation achieved an indexed BCPS blood flow of more $>100 \mathrm{~mL} / \mathrm{kg} / \mathrm{min}$. In a recent study of human SVC and BCPS flow, ${ }^{11}$ we demonstrated that baseline SVC flow close to or $>100 \mathrm{~mL} / \mathrm{kg} / \mathrm{min}$ was predictive of favorable BCPS outcome. This may support the idea of sourcing additional RA blood to augment pulmonary blood flow. $\mathrm{SaO}_{2}$ appeared to be more stable with the additional drainage from the RA, although we found no perceptible data comparing sole SVC drainage and additional RA drainage, likely owing to the small study population. Systemic perfusion was evaluated with arterial pressure and mixed venous saturation, which were stable and comparable to those in Norwood physiology. $\mathrm{VO}_{2}$ in the 2 patients was lower during SVC-PA pump assist compared with Norwood physiology. This findings is predictable based on previous $\mathrm{VO}_{2}$ measurements in BCPS physiology, although drawing any clear conclusion is premature given our small sample size. $\mathrm{rCTO}_{2}$ and $\mathrm{CPP}$ were maintained by effective decompression of the upper venous system. Overall, the physiology achieved with SVC-PA pump assist was compatible with survivability for the duration of the study in neonates who had just undergone a Norwood procedure.

\section{SVC-RA Oxygenation Assist}

This mode of mechanical assist is based on the idea of a partial artificial lung (or partial veno-venous extracorporeal membrane oxygenation equivalent) with various degrees of native lung perfusion depending on the pump flow. With full assist or 50\% assist, patients during the SVC-RA oxygenation assist had comparable hemodynamic and blood gas data and cerebral perfusion profile to values with BCPS physiology. There were some declines in $\mathrm{SaO}_{2}$ and $\mathrm{rCTO}_{2}$ during $25 \%$ assist. Not evident in the data but observed was the finding that maintaining $\mathrm{SaO}_{2}$ and $\mathrm{rCTO}_{2}$ at lower flow rates required an increase in filling pressure in the SVC to 12 to $15 \mathrm{~mm} \mathrm{Hg}$. This suggests that there is a critical filling pressure required to drive effective pulmonary blood flow for the lung portion of oxygenation and ventilation. Sufficient upper venous decompression and subsequent effective CPP were observed with various pump flows, although the patients in this particular model had a nearly normal PVR; thus, we cannot know the actual impact of low flow assist on SVC pressure in the setting of high PVR in neonates. The SVC-RA oxygenation assist system has an advantage in that oxygenation and $\mathrm{CO}_{2}$ exchange are at least partially independent of the immaturity of lung vasculature or PVR. Nonetheless, lower perfusion in the pulmonary circulation may or may not have a negative impact on the natural maturing process of lung vasculature. This remains to be determined by further basic and clinical studies. Another concern is the presence of an oxygenator in the circuit, which poses a risk of thrombosis, and necessitates a higher level of anticoagulation. Overall, this type of mechanical assist system functioned well, with no hemodynamic or physiological compromise for the duration of the study.

\section{Potential Problems and Future Direction}

Some significant problems remain to be solved before attempting a mechanically assisted approach clinically. Currently we lack a reliable device to implement these modes of mechanical assist in a chronic setting. Because the of the very low pump flow required (only up to $400 \mathrm{~mL} / \mathrm{min}$ ), the pump must have excellent antithrombogenic properties; however, historically this has not been the case. ${ }^{15}$ There was hope that new devices under development may be suitable for this mechanical assist application, but these are far away from clinical application and might not be applicable to this particular mode of mechanical assist. ${ }^{16}$ Another issue is that both mechanical assist strategies tested require SVC cannulation. Chronic injury to, and potential thrombosis of, the SVC could be a major challenge. Patency of the SVC is particularly important in patients undergoing staged single-ventricle palliation. The data also raise the possibility that in some neonates, SVC blood flow alone might not reach the threshold volume needed to predict adequate oxygenation and ventilation even with an efficient mechanism om place for doing so.

Additional enrollment will certainly provide more robust physiological data on this mechanical support system; nonetheless, this study does not address some of the important questions regarding the implications of chronic mechanical assist on PA and lung maturation and SVC thrombosis. Given the immaturity of the system, we are not ready to apply this strategy as an alternative to stage I Norwood palliation; rather, we would consider applying this strategy as salvage for patients with a failing Norwood physiology characterized by obvious low cardiac output, intolerance to chronic volume overload of the shunt physiology, or progressive ventricular and atrioventricular valve dysfunction who are at a significant risk for interstage death. For this purpose, the duration of mechanical assist can be relatively short, ranging from 4 to 12 weeks, until PVR becomes sufficiently low to sustain a BCPS physiology.

One idea to potentially solve the problem of SVC thrombosis is to use a ringed polytetrafluoroethylene (PTFE) tube 
graft (GORE-TEX; W.L. Gore \& Associates, Flagstaff, Ariz) as a "cannula" sewn to the SVC and PA in an endto-side fashion. This technique allows no material in the lumens, thereby minimizing the risks of thrombosis and endothelial injury. The combination of a ringed PTFE graft and a next-generation centrifugal pump, such as a CentriMag (Thoratec, Calif), would be the most likely device choice, because both are already clinically available.

\section{Study Limitations}

This study has some significant limitations. Enrollment in the study was challenging. The data obtained are meaningful but limited, precluding a definitive statistical analysis. Because the study was limited to 20 minutes, the impact of the physiology on lung maturation, long-term ventricular function, atrioventricular valve function, thrombosis, and other issues is not known. Clinical hypotheses, but not conclusions, can be generated.

\section{CONCLUSIONS}

Both tested types of simulated mechanical cavopulmonary assist in neonates and infants were found to be feasible in the acute setting. The study was performed to test the idea of a primary in-series palliation. Both modes of mechanical assist maintained hemodynamic stability, oxygenation, and systemic and cerebral perfusion.

\section{Conflict of Interest Statement}

G.S.V. has equity ownership of CellAegis. All other authors have nothing to disclose with regard to commercial support.

The authors thank Mr. Nobuko Yamamoto for the illustrations.

\section{References}

1. Ohye RG, Sleeper LA, Mahony L, Newburger JW, Pearson GD, Lu M, et al. Comparison of shunt types in the Norwood procedure for single-ventricle lesions. N Engl J Med. 2010;362:1980-92.

2. Baba K, Kotani Y, Chetan D, Chaturvedi RR, Lee KJ, Benson LN, et al. Hybrid versus Norwood strategies for single-ventricle palliation. Circulation. 2012; 126(11 Suppl 1):S123-31.

3. Wilder TJ, McCrindle BW, Phillips AB, Blackstone EH, Rajeswaran J, Williams WG, et al. Survival and right ventricular performance for matched chil- dren after stage-1 Norwood: modified Blalock-Taussig shunt versus rightventricle-to-pulmonary-artery conduit. J Thorac Cardiovasc Surg. 2015;150: 1440-52.e1-8.

4. Norwood WI, Kirklin JK, Sanders SP. Hypoplastic left heart syndrome: experience with palliative surgery. Am J Cardiol. 1980;45:87-91.

5. Reddy VM, Liddicoat JR, Hanley FL. Primary bidirectional superior cavopulmonary shunt in infants between 1 and 4 months of age. Ann Thorac Surg. 1995;59: 1120-5; discussion 1125-26.

6. Honjo O, Merklinger SL, Poe JB, Guerguerian AM, Alghamdi AA, Takatani S, et al. Mechanical cavopulmonary assist maintains pulmonary and cerebral blood flow in a piglet model of a bidirectional cavopulmonary shunt with high pulmonary vascular resistance. J Thorac Cardiovasc Surg. 2009;137: 355-61.

7. Honjo O, Merklinger SL, Poe J, Guerguerian AM, Alghamdi AA, Takatani S, et al. A novel mechanical lung assist system sustains primary bidirectional cavopulmonary shunt circulation in pigs. ASAIO J. 2007;53:720-4.

8. Merklinger SL, Honjo O, Al-Radi OO, Poe J, Wang J, Oka N, et al. Primary inseries palliation of hypoplastic left heart syndrome with mechanical lung assist in neonatal pigs. ASAIO J. 2009;55:620-5.

9. Naik SK, Knight A, Elliott MJ. A successful modification of ultrafiltration for cardiopulmonary bypass in children. Perfusion. 1991;6:41-50.

10. Burkhart HM, Ashburn DA, Konstantinov IE, De Oliveira NC, Benson L, Williams WG, et al. Interdigitating arch reconstruction eliminates recurrent coarctation after the Norwood procedure. J Thorac Cardiovasc Surg. 2005; 130:61-5.

11. Kotani Y, Honjo O, Shani K, Merklinger SL, Caldarone C, Van Arsdell G Is indexed preoperative superior vena cava blood flow a risk factor in patients undergoing bidirectional cavopulmonary shunt? Ann Thorac Surg. 2012;94: $1578-83$.

12. Li J, Zhang G, Holtby H, Guerguerian AM, Cai S, Humpl T, et al. The influence of systemic hemodynamics and oxygen transport on cerebral oxygen saturation in neonates after the Norwood procedure. J Thorac Cardiovasc Surg. 2008; 135:83-90.e1-2.

13. Chetan D, Kotani Y, Jacques F, Poynter JA, Benson LN, Lee KJ, et al. Surgical palliation strategy does not affect interstage ventricular dysfunction or atrioventricular valve regurgitation in children with hypoplastic left heart syndrome and variants. Circulation. 2013;128(11 Suppl 1):S205-12.

14. Jean-St-Michel E, Chetan D, Schwartz SM, Van Arsdell GS, Floh AA, Honjo O et al. Outcomes in patients with persistent ventricular dysfunction after stage I palliation for hypoplastic left heart syndrome. Pediatr Cardiol. 2016; $37: 239-47$.

15. Hetzer R, Potapov EV, Stiller B, Weng Y, Hübler M, Lemmer J, et al. Improvement in survival after mechanical circulatory support with pneumatic pulsatile ventricular assist devices in pediatric patients. Ann Thorac Surg. 2006;82 917-24; discussion 924-925.

16. Baldwin JT, Borovetz HS, Duncan BW, Gartner MJ, Jarvik RK, Weiss WJ. The national heart, lung, and blood institute pediatric circulatory support program: a summary of the 5-year experience. Circulation. 2011;123:1233-40.

Key Words: bidirectional cavopulmonary shunt, in-series palliation, mechanical circulatory assist, single-ventricle physiology 